\title{
Energy benefits of cement-based plaster containing hybrid phase-change material
}

\author{
Mohammad Kheradmand PhD \\ Post doctoral Fellow, RISCO, Civil Engineering Department, \\ University of Aveiro, Portugal; C-TAC, Civil Engineering Department, \\ University of Minho, Portugal; C-MADE, Civil and Architecture Department, \\ University of Beira Interior, Portugal (corresponding author: \\ mohammadkheradmand@hotmail.com) \\ Miguel Azenha PhD \\ Assistant Professor, ISISE, Civil Engineering Department, University of \\ Minho, Portugal
}

João Paulo Castro-Gomes PhD

Full Professor, C-MADE, Civil and Architecture Department, University of Beira Interior, Portugal

Jose Luis Barroso de Aguiar PhD

Associate Professor, C-TAC, Civil Engineering Department, University of Minho, Portugal

This paper reports an experimental study regarding the energy-saving potential of an innovative concept of thermal energy storage, which consists of embedding three types of phase-change material (PCM) into a cement-based mortar for plastering the inside walls of buildings. The so-called 'hybrid phase-change material mortars' can enhance energy saving when compared with single PCM mortars. They increase the range of melting temperatures and enthalpies, thus providing a more staged and progressive energy exchange. The experimental programme comprised two hollow boxes, one internally rendered with hybrid mortar and the other with a reference mortar without PCM. They were then externally subjected to realistic daily winter temperature profiles. The prototypes were internally equipped with a heater programmed to keep the inside of the boxes at a comfortable room temperature. The energy consumption in the box rendered with hybrid mortar was nearly $20 \%$ less than that of the box rendered with standard mortar. The potential cost savings of hybrid PCM mortars for residential buildings are also discussed.

\section{Notation \\ $\operatorname{DSC}(T)_{\text {baseline }}$ value of differential scanning calimetry (DSC) signal at temperature $T$ from the baseline of the thermogram for the phase change $(\mathrm{mW} / \mathrm{mg})$ \\ $\operatorname{DSC}(T)_{\text {sample }} \quad$ value of DSC signal at temperature $T$ from the thermogram $(\mathrm{mW} / \mathrm{mg})$ \\ $I_{\mathrm{g}} \quad$ global solar radiation $\left(\mathrm{W} / \mathrm{m}^{2}\right)$ \\ $R_{\text {se }} \quad$ external surface resistance $\left(\left(\mathrm{m}^{2} \mathrm{~K}\right) / \mathrm{W}\right)$ \\ $T \quad$ temperature $\left({ }^{\circ} \mathrm{C}\right)$ \\ $T_{\text {Air }} \quad$ exterior temperature $\left({ }^{\circ} \mathrm{C}\right)$ \\ $T_{\text {onset }} \quad$ onset temperature $\left({ }^{\circ} \mathrm{C}\right)$ \\ $T_{\text {Sol-Air }} \quad$ sol-air temperature \\ $\alpha \quad$ absorption coefficient of the surface \\ $\phi \quad$ heating rate $\left({ }^{\circ} \mathrm{C} / \mathrm{s}\right)$}

\section{Introduction}

Thermal energy storage systems can assist the reduction of indoor temperature variations, and also shift the energy loads in buildings from peak hours towards off-peak hours of energy demand. It has been shown that buildings are responsible for a significant portion of the world's energy demand, which is linked to the growth rate of the population as well as the global tendency for improvement of societal demands/awareness regarding indoor thermal comfort (Halford and Boehm, 2007). In particular, the indoor heating and cooling systems used in buildings are among the most energy-demanding uses, corresponding to about $30 \%$ of energy used in this sector (Sayyar et al., 2014). Therefore, it is relevant to develop systems that can assist in maintaining indoor temperature within comfort levels, while helping in the reduction of energy consumption for such purpose. The storage of energy improves the energy efficiency in buildings by allowing the energy to be used more rationally. The materials that benefit from latent heat storage are normally called phase-change materials (PCMs) (Duffie and Beckman, 1980). Latent heat storage can be explained simply as follows: when the temperature increases a given solid PCM reaches its melting threshold, and the phase change occurs with relevant heat absorption. An opposite mechanism takes place in the change of state from liquid to solid, with heat liberation occurring in such processes. These energy absorption/release processes mean that the PCM tends to enforce a stable temperature situation on itself, which is a very favourable situation from the point of view of being able to maintain a target temperature in a given room. A suitable PCM for a particular application should provide the desirable phase-change temperature, high latent heat capacity, durability under heating/cooling cycles and thermal conductivity; it should also be non-toxic, non-flammable, noncorrosive and economic to use (Zhou et al., 2012).

One potential methodology for enhancing energy saving in buildings is the use of PCMs incorporated or even embedded into building materials. Typical PCMs that are desirable for building applications include salt hydrates, fatty acids and paraffins. Paraffins have many desirable properties among other types of the PCMs, such as negligible super cooling, high latent heat, stability and resistance to phase segregation (Hasnain, 1998). 


\section{Offprint provided courtesy of www.icevirtuallibrary.com Author copy for personal use, not for distribution}

However, they have low thermal conductivity and also are rather costly due to the fact that, in their liquid state, the PCMs require containment (encapsulations), which increases the cost of the final product. Several researchers have investigated methods for incorporating PCM into construction materials such as plastering mortars (Vaz Sá et al., 2012), concrete slabs (Bentz and Turpin, 2007) and bricks (Vicente and Silva, 2014). The incorporation of PCMs within the outside envelopes of buildings (e.g. plastering mortars) can make them particularly feasible for capturing solar energy directly and storing significant amounts of thermal energy in the building envelopes. On the contrary, incorporation of PCM into the plastering mortars of buildings can improve the thermal efficiency of the buildings owing to their ability to store energy and allows a reduction in the energy consumption of heating/cooling systems used to control the indoor temperature of the room (Waqas and Zia, 2013).

Shafie-Khah et al. (2016) studied an operational model of a home energy management system considering the incorporation of more than one type of PCM in plastering mortars (hybrid PCM) as well as single PCM, proposed not only to minimise the customer's cost in different demand response programming (DRP) but also to guarantee the occupants' satisfaction. Moreover, the proposed model ensures the technical and economic limits of batteries and electrical appliances. Different case studies indicate that implementation of hybrid PCM in the buildings can meaningfully affect the operational pattern of home energy management systems in different DRPs. In terms of the energy-saving potential of the system, the case studies indicate that the hybrid PCM mortar can offer better potential for energy saving when compared with the single PCM type. Even though the potential energy saving of the single PCM scenario was already quite satisfactory, the hybrid PCM has added value without predictable added cost.

In this study, hybrid paraffin-based PCMs were used in the same mortar, here termed as hybrid PCM mortar (HPCMM), using more than one type of $\mathrm{PCM}$ with distinct melting ranges and specific enthalpies. The hybrid PCM was incorporated into cement-based plastering mortar, and the thermal performance of this mortar was evaluated using a small-scale prototype (hollow enclosure rendered with HPCMM), equipped with an internal heater and subjected to a daily temperature profile comparable to a typical winter's day in the north of Portugal. An additional prototype comprising a coating mortar without any kind of PCM was also prepared and tested for comparative purposes. It is noted that the internal heater was connected to a thermostat set to keep the inside of the tested box within a predefined thermal comfort temperature range. The energy consumption of the heater during the process of testing was assessed with an energy meter for both HPCMM and REFM prototypes.

\section{Experimental programme}

\subsection{Materials and formulations}

The initial selection of materials for this research was limited to those exhibiting phase change in the temperature range of 5-30 ${ }^{\circ} \mathrm{C}$, which covers the sol-air temperature variations in the typical winter climatic conditions of the location of the building, in southern European countries (such as Portugal) as well as representing the thermal comfort range. In this way, three types of paraffin-wax-based (organic) PCMs were considered for the experimental programme reported herein: RT10 with melting temperature of $10^{\circ} \mathrm{C}$ (from Rubitherm paraffin RT series (Rubitherm GmbH, 2012)), MC28 with melting temperature of $28^{\circ} \mathrm{C}$ (from Devan Micropolis MC series (DM, 2012)) and BSF26 with melting temperature of $26^{\circ} \mathrm{C}$ (from BASF microencapsulated Micronal series DS 5001 (BASF, 2008)). The properties of the PCMs selected for this study are presented in Table 1. According to previous developments by this research team (Kheradmand et al., 2016), the formulation of mortars with incorporation of hybrid PCMs allowed the mass fraction of PCM to reach nearly $20 \%$ of the global mass of the mortar. It should be mentioned that the performance in terms of the main properties of the mortar was maintained at satisfactory levels, for example, the workability, compressive strength, flexural strength and adhesion (Cunha et al., 2015).

The mix designs of the two mortars studied herein, together with their adopted designations (REFM for the reference mortar and HPCMM for the hybrid PCM mortar) are presented in Table 2. It is noted that the formulation of mortars HPCMM adopted herein comprises the three distinct PCMs mentioned above, in line with previous works of this team (Kheradmand et al., 2016). The three PCMs have been weighed separately and blended together in a mixer for $3 \mathrm{~min}$, prior to the incorporation in the mortar mixture; it is noted that the three PCMs are placed in equal mass quantity, thus globally reaching $18 \cdot 34 \%$ of the weight of the mortar. It is interesting to

Table 1. Measured properties of PCMs

\begin{tabular}{|c|c|c|c|c|c|}
\hline $\begin{array}{l}\text { PCM } \\
\text { type }\end{array}$ & $\begin{array}{l}\text { Operating temperature } \\
\text { ranges: }{ }^{\circ} \mathrm{C}\end{array}$ & $\begin{array}{l}\text { Latent heat of } \\
\text { fusion: } \mathrm{J} / \mathrm{kg}\end{array}$ & $\begin{array}{l}\text { Melting } \\
\text { point: }{ }^{\circ} \mathrm{C}\end{array}$ & $\begin{array}{c}\text { Apparent density at solid } \\
\text { state: } \mathrm{kg} / \mathrm{m}^{3}\end{array}$ & $\begin{array}{c}\text { Particle size distribution } \\
\text { range: } \mu \mathrm{m}\end{array}$ \\
\hline RT10 & $2-12$ & 150000 & 10 & 880 & - \\
\hline BSF26 & $10-30$ & 110000 & 26 & 350 & $5-90$ \\
\hline MC28 & $22-32$ & 170100 & 28 & 359 & $14-24$ \\
\hline
\end{tabular}




\section{Offprint provided courtesy of www.icevirtuallibrary.com Author copy for personal use, not for distribution}

Table 2. Mix proportions of formulations REFM and HPCMM (including photographs at hardened stage)

\begin{tabular}{|c|c|c|c|c|}
\hline \multirow[b]{2}{*}{ Materials } & \multicolumn{4}{|c|}{ Formulations: $\%$ of the total weight of mortar } \\
\hline & & REFM & & HPCMM \\
\hline Cement type I-42.5R (SECIL) & $22 \cdot 64$ & & $31 \cdot 32$ & \\
\hline Sand & $64 \cdot 23$ & & $30 \cdot 59$ & \\
\hline Water & $12 \cdot 45$ & & $18 \cdot 79$ & \\
\hline Superplasticiser & 0.63 & & 0.94 & \\
\hline RT10 & - & & $6 \cdot 12$ & \\
\hline BSF26 & - & & $6 \cdot 12$ & \\
\hline MC28 & - & & $6 \cdot 12$ & \\
\hline
\end{tabular}

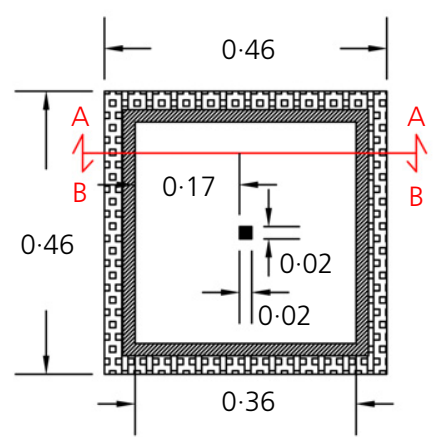

(a)

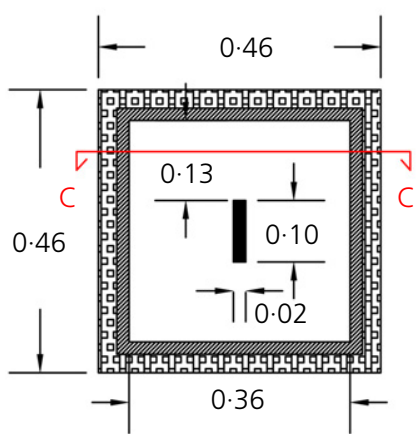

(b)

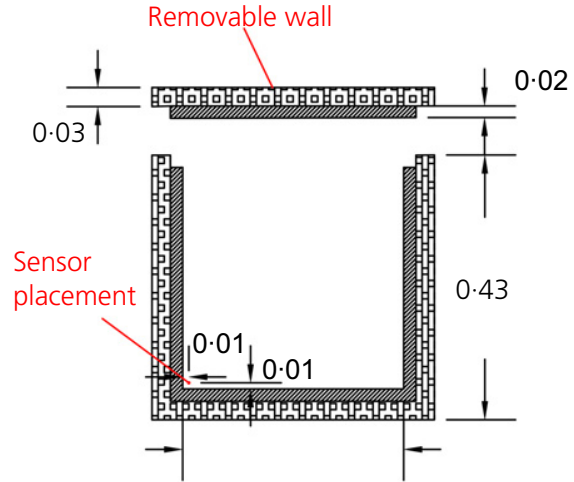

(c)

Figure 1. Schematic representation of the prototype equipped with a heater element placed inside the climatic chamber. Units: $m$. (a) Plan view $C-C$, (b) cross-section B-B, (c) sensor placements cross-section A-A

note that an adequate behaviour (i.e. absence of drying cracks) was obtained with both of the formulations - REFM and HPCMM.

The determination of the specific enthalpy of the mortar specimens was performed through differential scanning calorimetry (DSC) testing in a nitrogen atmosphere, with recourse to a Netzsch 200 F3 Maia, following the methodology recommended by EN ISO 11357-1 (ISO, 1997). One specimen was prepared for the study of HPCMM, with a weight of $37.88 \mathrm{mg}$. A heating rate of $2^{\circ} \mathrm{C} / \mathrm{min}$ was considered for the experiment. The applied programme steps for the test procedure of specimens are the following: $(a)$ initial isothermal period at $0^{\circ} \mathrm{C}$ for $5 \mathrm{~min}$; (b) dynamic heating up to $40^{\circ} \mathrm{C}$ according to the proposed rate $\left(2^{\circ} \mathrm{C} / \mathrm{min}\right)$.

\subsection{Design and fabrication of two-layered active system prototype}

To assess the effect of the hybrid PCM concept in plastering mortars used as internal coatings for energy saving in buildings, two closed prototypes equipped with a heater element were built with laboratory-scale dimensions. The outside of the prototype was cubic with an edge length of $0.46 \mathrm{~m}$. The prototypes were hollow, and the materials used for the construction of the prototype walls were (from inside to outside): a $0.02 \mathrm{~m}$ thick layer of REFM or HPCMM, and a $0.03 \mathrm{~m}$ thick layer of extruded polystyrene (XPS). The schematic diagram of the physical models and cross-section of the model are shown in Figure 1.

The composition of the walls of the prototype is not a typical one in building envelopes. In fact, the target in this study was to have a small prototype, with relatively thin walls, which would, however, have a thermal transmittance $\left(U \approx 0.89 \mathrm{~W} / \mathrm{m}^{2} \mathrm{~K}\right)$ lower than the maximum limit according to Portuguese regulations for vertical elements, which is $U=1.45 \mathrm{~W} / \mathrm{m}^{2} \mathrm{~K}$ (RCCTE (Camelo et al., 2006)), thus having a reasonably similar thermal behaviour to actual building envelopes.

The heating system was placed inside the prototype (centre of the heater coinciding with the geometrical centre of the cube) 


\section{Offprint provided courtesy of www.icevirtuallibrary.com Author copy for personal use, not for distribution}

as shown in Figure 1. The heater (Rotfil air-heater series) had dimensions of $0.02 \mathrm{~m} \times 0.02 \mathrm{~m} \times 0.1 \mathrm{~m}$, with a power rating of $300 \mathrm{~W}$. The heater was connected to a multifunctional electricity source with a temperature controller (Omron-E5CSV). The control of the heating system was made in order to maintain the temperature within the prototype within a predefined comfort level. The standard ASHRAE55 (ASHRAE, 2004) recommends that the air temperature inside residential buildings should be at least $\approx 20^{\circ} \mathrm{C}$ during the winter season. Temperature sensing was performed with a PT100 sensor (located as shown in Figure 1(c)), wired to an Agilent 34970A datalogger (22 bits). The energy supplied to the heater was measured with an Owl USB energy monitor.

\subsection{Physical test configuration}

The test set-up for a total number of two experiments (one for REFM and one for HPCMM) was performed under a typical Portuguese winter scenario. The sensor for controlling the heater element was attached to the bottom corner sensor inside the prototype, as this would be the coldest region within the prototype. The main comparative evaluation parameter of the performance of the two studied plastering mortars was the energy demand of the heater to maintain adequate internal comfort levels. The scheme illustrated in Figure 2(a) shows the temperature controller and the energy meter units programmed to measure/control the interior temperature of the prototype, which is attached to the placement of the bottom corner sensor (here termed IT), monitor

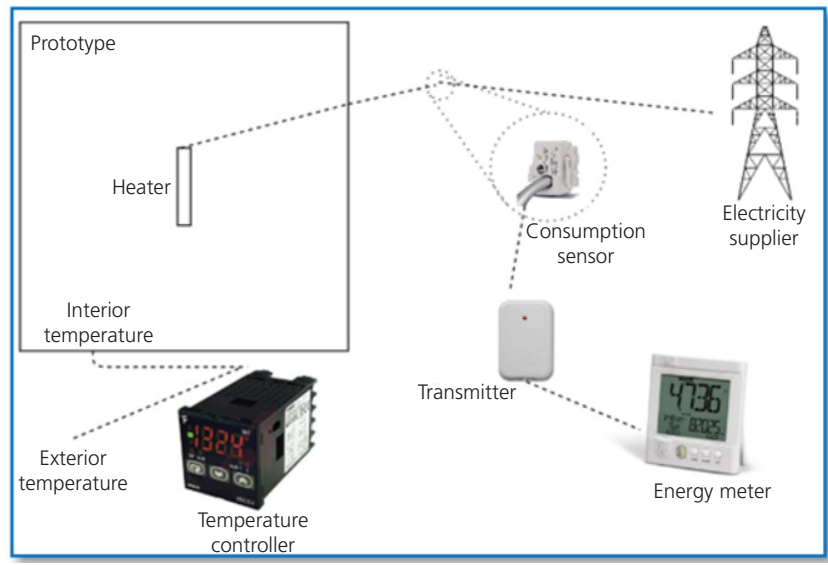

(a)

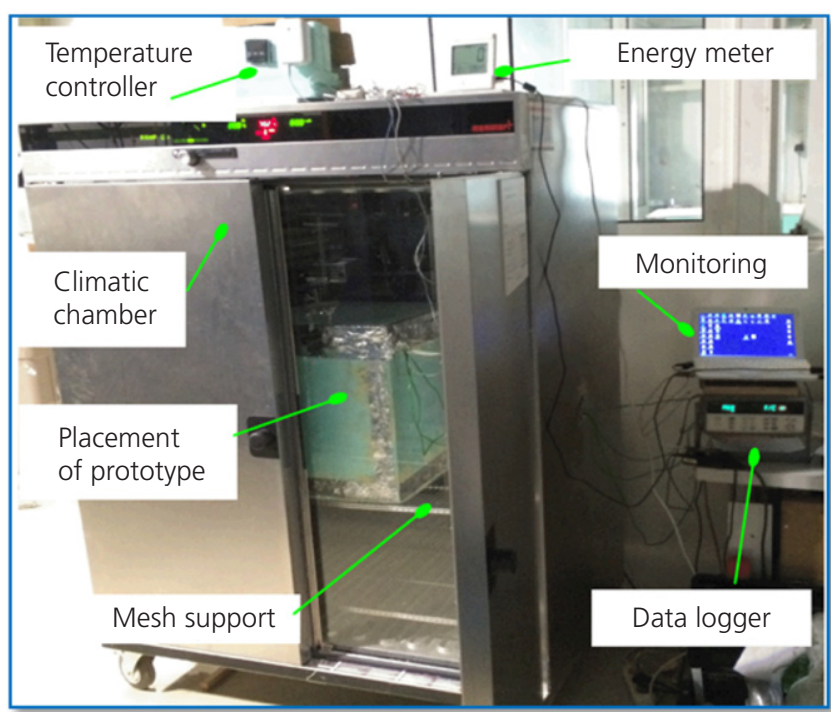

(c)

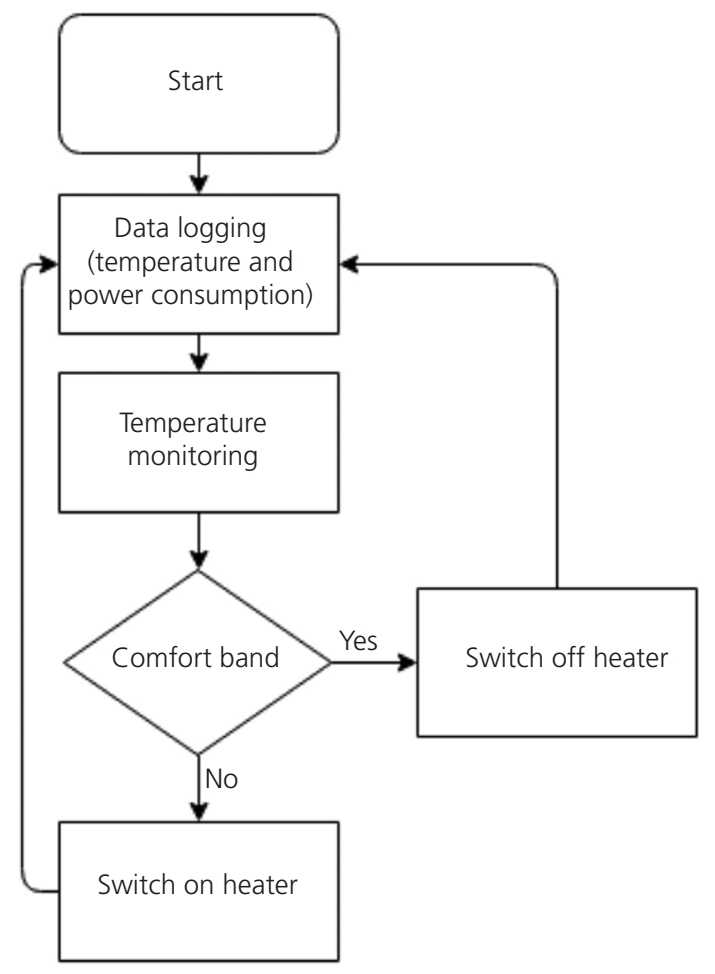

(b)

Figure 2. (a) Monitoring and control arrangement system scheme; (b) experimental procedure for the heater element; (c) photograph of the prototype ready for testing, highlighting the location of the prototype within the climatic chamber 


\section{Offprint provided courtesy of www.icevirtuallibrary.com Author copy for personal use, not for distribution}

the exterior temperature (placed at climatic chamber ambient), and assess the power consumption of the heating element unit. The operating principle of the devised system is presented in Figure 2(b). The heater comes on when the measured temperature inside the box is under $20^{\circ} \mathrm{C}$. Conversely, the heater is off when the temperature reaches (or surpasses) $20^{\circ} \mathrm{C}$. The IT sensor was connected to the data-acquisition system mentioned above. The electrical consumption of the heating units was measured using the dedicated energy meter. Each one of the two experiments was carried out for three full-day cycles $(72 \mathrm{~h})$. The climatic chamber in which the test was conducted also allowed the control of internal relative humidity $(\mathrm{RH})$, which was set to the constant value of $\mathrm{RH}=50 \%$ throughout all of the performed experiments. The physical arrangement of this set-up can be observed in the picture of the prototype/monitoring shown in Figure 2(c).

Each prototype was placed inside a controlled climatic chamber. The climatic chamber was programmed to follow temperature cycles that matched the sol-air temperature for a vertical wall facing south, located in the north of Portugal considering the winter scenario. The concept of sol-air temperature (O'Callaghan and Probert, 1977) has been adopted as to establish a fictitious outside air temperature which, in the absence of solar radiation (inside the climatic chamber), can give the same temperature distribution and rate of heat transfer through walls, as it exists due to the combined effects of the actual outside temperature and incident solar radiation. The sol-air temperature $\left(T_{\text {Sol-Air }}\right)$ was computed according to Equation 1 (Vaz Sá et al., 2012)

1. $T_{\mathrm{Sol} \pm \text { Air }}=T_{\mathrm{Air}}+\alpha I_{\mathrm{g}} R_{\mathrm{se}}$

$T_{\text {Air }}$ is the exterior temperature $\left({ }^{\circ} \mathrm{C}\right) ; \alpha$ is the absorption coefficient of the surface; $I_{\mathrm{g}}$ is the global solar radiation $\left(\mathrm{W} / \mathrm{m}^{2}\right)$; and $R_{\text {se }}$ is the external surface resistance $\left(\left(\mathrm{m}^{2} \mathrm{~K}\right) / \mathrm{W}\right)$. The values of the exterior temperature $\left(T_{\text {Air }}\right)$ and global solar radiation $\left(I_{\mathrm{g}}\right)$ were considered in terms of average hourly values recorded for a representative day of winter in Guimarães, obtained from a weather station located within the campus of the University of Minho. An absorption coefficient $\alpha=0.6$ was considered in correspondence to the colour of the surface material (XPS) (ISO 6946 (ISO, 2007)). The value of the external surface resistance was adopted as $R_{\mathrm{se}}=0.04\left(\mathrm{~m}^{2} \mathrm{~K}\right) / \mathrm{W}$ in accordance to the recommendations of ISO 6946 (ISO, 2007). As a result of the application of the sol-air temperature model, the $24 \mathrm{~h}$ cycle shown in Figure 3 was obtained for the winter scenario.

\section{Results and discussion}

\subsection{Characterisation of the mortars}

Phase-change temperature and specific enthalpy are two key properties of PCMs. Figure 4 shows the specific heat capacity of the HPCMM under a heating process as well as the corresponding calculated specific enthalpy.

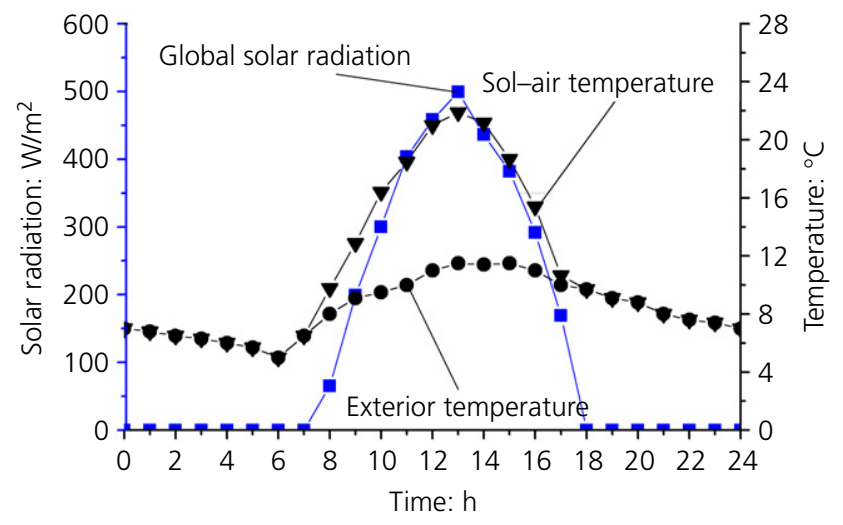

Figure 3. Exterior temperature, solar radiation and sol-air temperature of a winter's day in Guimarães, Portugal

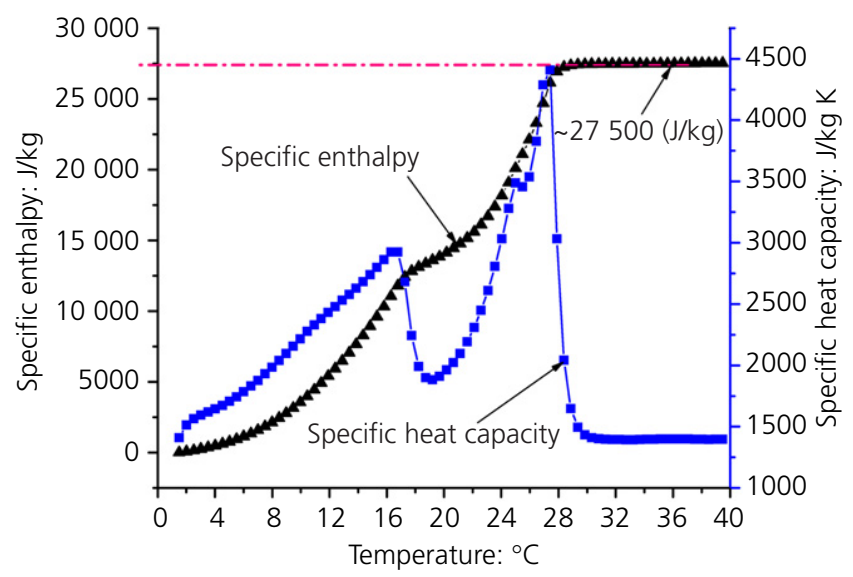

Figure 4. Specific heat capacity and specific enthalpy for HPCMM mortar with heating rates of $2^{\circ} \mathrm{C} / \mathrm{min}$

The first, second and third peak temperatures in the specific heat capacity curve belong to the RT10, BSF26 and MC28 with melting temperatures around 15,24 and $26^{\circ} \mathrm{C}$, respectively (Figure 4). It should be stated that, for the sake of brevity, the DSC testing of the reference mortar (REFM) that did not contain any PCM, was just a straight line, confirming that such material did not endure any internal phase-change transition. Therefore, there will be no further discussion of the REFM mortar.

To calculate the specific enthalpy $H(T)$ of the mortar with PCM, based on the DSC output, the calculation procedure for each phase change followed Equation 2:

2. $H(T)=\frac{1}{\phi} \int_{T_{\text {onset }}}^{T}\left[\operatorname{DSC}(T)_{\text {sample }}-\operatorname{DSC}(T)_{\text {baseline }}\right] \mathrm{d} T$ 


\section{Offprint provided courtesy of www.icevirtuallibrary.com Author copy for personal use, not for distribution}

where $\operatorname{DSC}(T)_{\text {sample }}$ is the value of the DSC signal at temperature $T$ from the thermogram $(\mathrm{mW} / \mathrm{mg}), \operatorname{DSC}(T)_{\text {baseline }}$ is the value of the DSC signal at temperature $T$ from the baseline of the thermogram for the phase change $(\mathrm{mW} / \mathrm{mg}), \phi$ is the heating rate $\left({ }^{\circ} \mathrm{C} / \mathrm{s}\right), T_{\text {onset }}$ is the onset temperature $\left({ }^{\circ} \mathrm{C}\right)$ and $T$ is the temperature $\left({ }^{\circ} \mathrm{C}\right)$. The results of the calculation of specific enthalpy evolution with temperature for HPCMM are shown in Figure 4. It can be observed that the accumulated specific enthalpy is about $27500 \mathrm{~J} / \mathrm{kg}$.

\subsection{Thermal performance and energy-saving potential of mortars}

Figure 5(a) shows the air temperature variations recorded inside the REFM prototype over a $24 \mathrm{~h}$ period (second cycle), represented together with the externally imposed temperature, as well as the information about the periods in which the heater was activated by the control system. As shown in Figure 5(a), during a cycle of $24 \mathrm{~h}$, the interior air temperature was adequately kept at the minimum comfort temperature of about $20^{\circ}$ $\mathrm{C}$ according to the predefined set-point temperature for the heater. During the first $9 \mathrm{~h}$ period, when the ambient temperature was under about $14^{\circ} \mathrm{C}$, the heater experienced both modes of off and on with small intervals so as to maintain the interior temperature of the prototype at the limit temperature of $20^{\circ} \mathrm{C}$. Between the instants $t \approx 9 \mathrm{~h}$ and $t \approx 17 \mathrm{~h}$, the effect of the thermal inertia of the walls seems to have been enough to ensure the $20^{\circ} \mathrm{C}$ temperature inside the prototype without the need for activation of the heater system.

The results of thermal behaviour in the hybrid PCM prototype (HPCMM) are shown in Figure 5(b). In fact, Figure 5(b) is

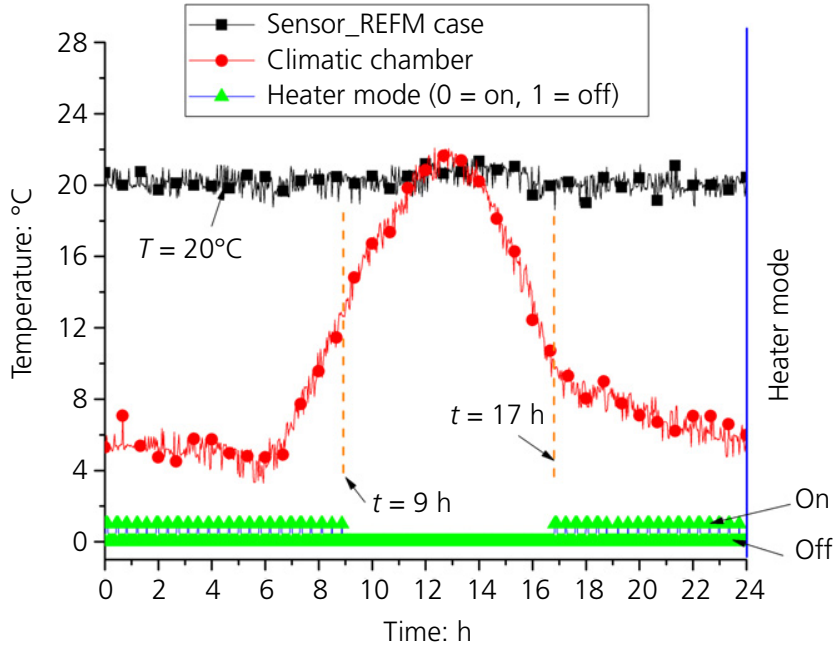

(a) homologous to Figure 5(a), except for the fact that it deals with HPCMM. The observations are also analogous to those already made for REFM. In brief, in the case of HPCMM there is a possibility of taking advantage of PCMs due to the fact that they can absorb or release the heat during their phase-change temperatures, and therefore the necessity of activation of the heater is felt for smaller durations. For further evaluation of the impact of the PCM on thermal efficiency of the system, the cumulative energy consumptions by the heater equivalent to both the cases of REFM and HPCMM were calculated for a period of $24 \mathrm{~h}$ and are demonstrated in Figure 6. The configuration with PCM allowed approximately 20\% reduction in energy demands for maintaining the temperature inside the prototypes within the comfort temperature. This shows that the electricity saving achieved each day comes from PCMs and is affected by outdoor temperature.

\subsection{Global energy-saving potential of PCM-based system}

The studies presented in this section are based on the simplifying assumption that the energy demand in an actual building could be similar to the one identified in the tested box, and cost analyses are performed according to realistic electricity tariffs in the market. Even though this is not necessarily realistic, it still provides an interesting insight into the combination of the thermal storage of the PCM with the actual benefits that can be harvested from electricity pricing that varies during the day.

Figure 7 shows residential electricity costs for different tariffs based on the available price list provided by one of the main

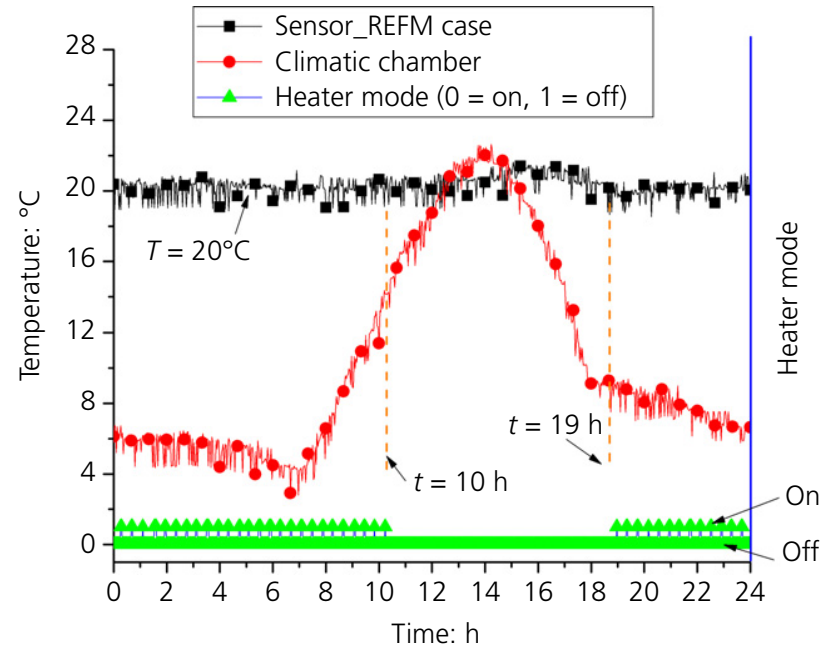

(b)

Figure 5. Monitoring temperature variations at different positions inside the prototypes equipped with heater under controlled environmental condition for: (a) REFM case and (b) HPCMM case 


\section{Offprint provided courtesy of www.icevirtuallibrary.com Author copy for personal use, not for distribution}

electricity suppliers in Portugal (EDP - Eletricidade de Portugal). The price of energy in the illustrated plans is variable throughout the day, except for the flat-rate plan that actually keeps to a constant value. In fact, the electricity prices are different in different hours. Each tariff encourages electricity use in response to fluctuations of its price over time, by offering cheaper prices for energy use in off-peak periods, and increasing energy prices in periods of the day that normally correspond to high energy demand. Five profiles of demand response programmes are considered: flat rate, time of use 1

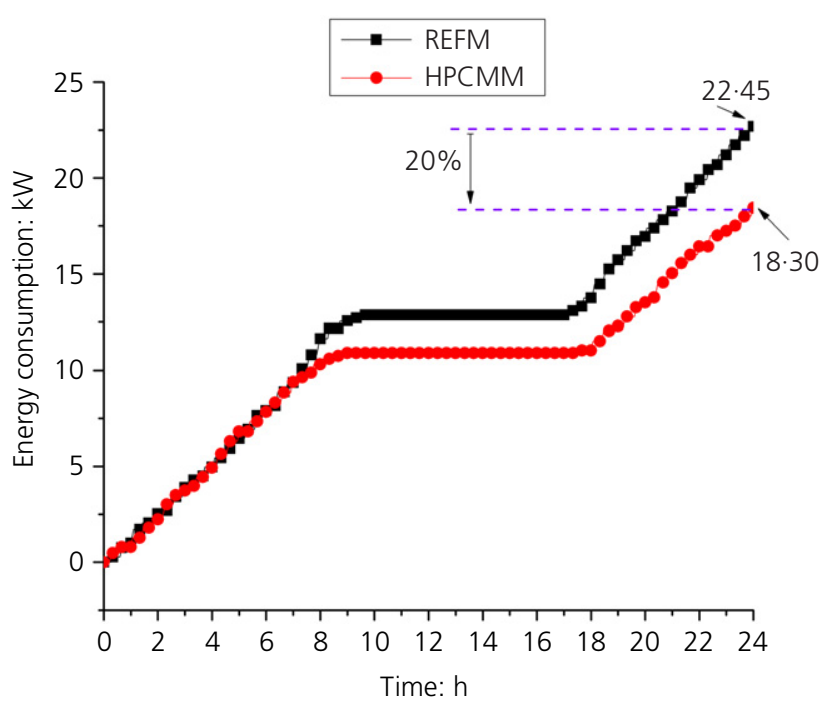

Figure 6. Cumulative energy consumption against time

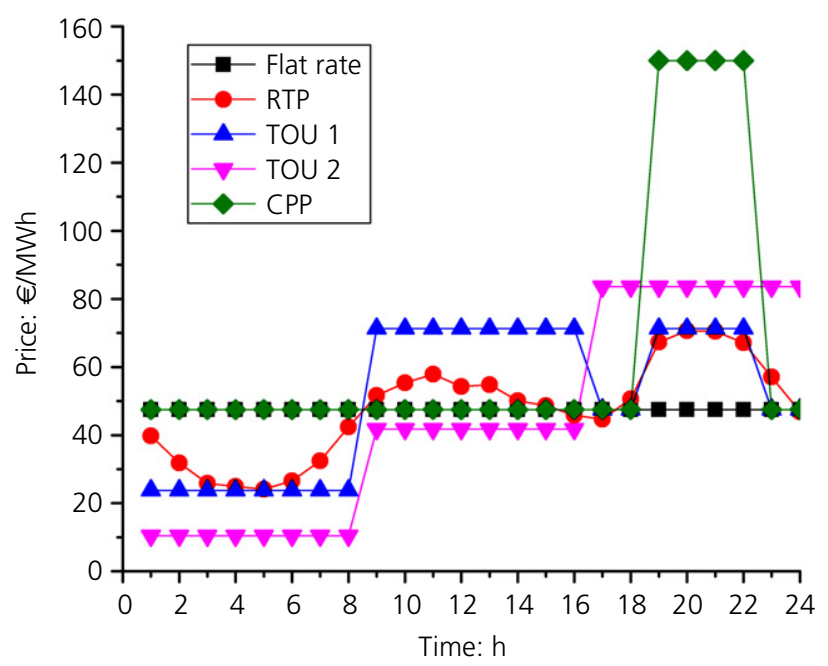

Figure 7. Hourly prices of the energy market. RTP, real-time pricing; TOU, time of use and CPP, critical peak pricing
(TOU1), time of use 2 (TOU2), real-time pricing (RTP) and critical peak pricing (CPP). The RTP tariff varies dynamically according to the electricity demand on the national grid. Both TOU1 and TOU2 tariffs have similar structures, with constant prices for given periods of time during the day. The CPP tariff structure is similar to flat rate except that a peak price band was introduced between 18:00 and 23:00 h.

On the basis of the actual energy consumptions reported in the previous section, and the variable pricing of energy shown in Figure 7, different cost scenarios could be computed according to each tariff.

Figure 8 illustrates the load data that were taken from the actual consumption of prototypes $\left(0 \cdot 26 \mathrm{~m}^{3}\right)$ in the experiments reported in the previous section for a representative winter's day in Portugal. These data confirm that the energy consumption for heating the interior in the case is actually globally lower for HPCMM, when compared to REFM. Furthermore, the HPCMM contributes to the shifting of the electricity consumption during the entire testing period of $1 \mathrm{~d}$, when compared with REFM. The energy cost estimation for the same period of $24 \mathrm{~h}$, taking into account the above-mentioned tariffs, is shown in Figure 9. It can be seen that tariff CPP brings significantly higher energy costs than the flat-rate scenario. In spite of that, the HPCMM mortar can reduce consumption by nearly $20 \%$ when compared to REFM. In any case, the option of selecting CPP is not attractive at all in view of its increased price. Apart from CPP, which resulted in the highest expenditure for the final user, all other non-flat-rate plans ended up offering benefits to the user, which were invariably better for HPCMM than for REFM. The best saving was achieved in TOU2, with reductions in payment of 18 and $15 \%$

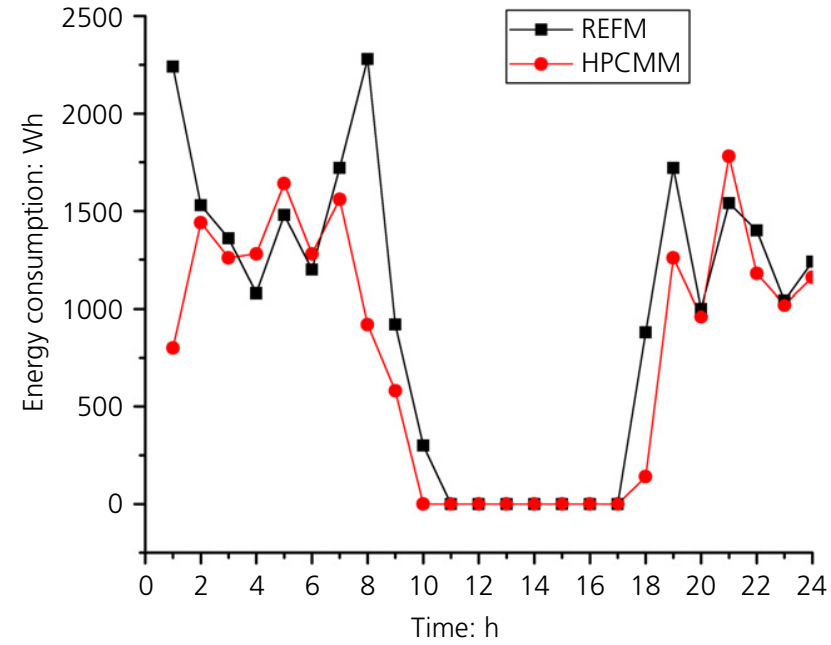

Figure 8. Space heating consumption with and without PCM 


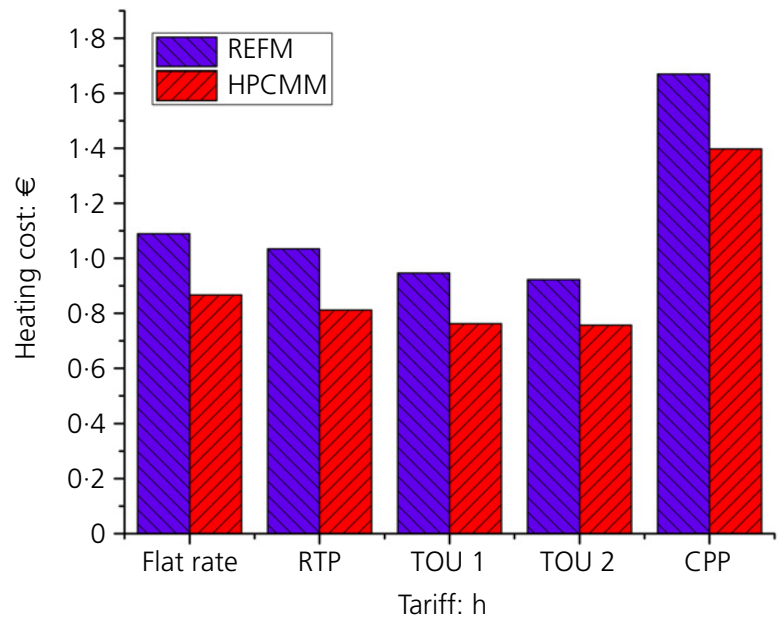

Figure 9. Energy demand cost during the tested winter's day

with regard to the flat-rate scenario for REFM and HPCMM, respectively.

If the global saving is analysed by comparing the expenditure in energy of the best-performing scenario (HPCMM with TOU2 tariff) with the initial reference scenario (REFM with flat-rate tariff), the total savings can be calculated as $30 \cdot 5 \%$, which clearly demonstrates the synergetic effect of variable energy rates and the use of PCMs in building plasters (reduction and shifting of energy consumption).

\section{Conclusions}

This paper presents the thermal characterisation (DSC) of mortars containing incorporated PCMs targeted for thermal comfort in buildings. The study encompasses a reference mortar termed REFM, as well as a mortar containing hybrid PCMs (called HPCMM) with mass fraction of $18.34 \%$ of PCM with melting temperatures of 10,26 and $28^{\circ} \mathrm{C}$. The hybrid blend of three distinct types of PCMs has proved advantageous for improved efficiency in the thermal comfort assurance in buildings (reducing energy consumption for heating/cooling seasons). The feasibility at material/thermal level as well as energy-saving potential was evaluated in this work.

From the material level investigation, the thermal behaviour of the PCM mortar has been analysed, specifically with regard to the peak temperatures in the specific heat capacity, as well as the calculated specific enthalpy. Regarding specific heat capacity curves, it was found that, hybrid PCM mortar containing three individual PCMs with different melting temperature which illustrated three peaks, accordingly. Furthermore, the calculated specific enthalpy for phase transition was obtained based on the considered heating rate.
A two-layered wall prototype enclosure was designed to complement the high latent heat storage capacity and energy-saving potential of hybrid PCM through laboratory-scale testing. The prototype incorporated hybrid PCM mortar. A second prototype with a reference mortar that did not contain any PCM was also made and tested for comparative purposes. The energy-saving results indicated a reduction of $20 \%$ in energy demand to maintain the interior within the thermal comfort range by application of the hybrid PCM mortar. These results confirmed the important benefits of hybrid PCM mortar in terms of energy efficiency, thermal comfort and energy cost saving.

This method of latent heat storage can further benefit from variable electricity prices during the day by shifting the peak load of consumption. It is, however, noted that the melting point of the PCM needs to be selected according to the thermal comfort requirements.

If the savings provided by HPCMM are combined with energy tariffs that favour off-peak utilisation of energy, the benefits of HPCMM with regard to REFM are slightly improved with regard to the flat-rate scenario. Indeed, the $20 \%$ saving by using HPCMM as opposed to REFM in a flat-rate energy tariff can vary when a realistic variable tariff is considered. It was demonstrated that the combination of using HPCMM with the energy tariff TOU2 brings even further benefits when comparisons are made with reference scenarios.

\section{Acknowledgements}

The authors gratefully acknowledge the Portuguese Foundation for Science and Technology (FCT) for the financial support to the Research Units of C-MADE, C-TAC and ISISE, as well as to the research projects PTDC/ECM/102154/ 2008 and the EU 7th Framework Program FP7/2007-2013 under grant number 395309048 (SiNGULAR).

\section{REFERENCES}

ASHRAE (American Society of Heating, Ventilating and Air-Conditioning Engineers) (2004) Standard 55-2004: Thermal environment conditions for human occupancy. American Society of Heating, Ventilating and Air-Conditioning Engineers, Atlanta, GA, USA. BASF (Badische Anilin- und Soda-Fabrik (Baden Aniline and Soda Factory)) (2008) Micronal PCM. Intelligent Temperature Management for Buildings. BASF, Ludwigshafen, Germany. Bentz DP and Turpin R (2007) Potential applications of phase change materials in concrete technology. Cement and Concrete Composites 29(7): 527-532.

Camelo S, dos Santos CP, Ramalho Á et al. (2006) Regulamento das Características do Comportamento Térmico dos Edificios-Manual de apoio à aplicação do RCCTE. INETI, Lisboa, Portugal (in Portugese).

Cunha S, Aguiar J, Ferreira V and Tadeu A (2015) Mortars based in different binders with incorporation of phase-change 


\section{Offprint provided courtesy of www.icevirtuallibrary.com} Author copy for personal use, not for distribution

materials: physical and mechanical properties. European Journal of Environmental and Civil Engineering 19(10): 1216-1233.

DM (Devan Microthermic) (2012) PCM. THERMIC Temperature

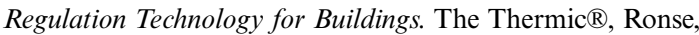
Belgium.

Duffie JA and Beckman WA (1980) Solar Engineering of Thermal Processes. John Wiley \& Sons, Inc., New York, NY, USA.

Halford CK and Boehm RF (2007) Modeling of phase change material peak load shifting. Energy and Buildings 39(3): 298-305.

Hasnain SM (1998) Review on sustainable thermal energy storage technologies, Part I: heat storage materials and techniques. Energy Conversion and Management 39(11): 1127-1138.

ISO (International Organization for Standardization) (1923) ISO 6946: 2007 Building components and building elements - Thermal resistance and thermal transmittance - Calculation method. ISO, Geneva, Switzerland

ISO (1997) EN ISO 11357-1. Plastics - Differential scanning calorimetry (DSC) Part 1: General principles. DIN Deutsches Institut für Normung e.V., Berlin, Germany.

Kheradmand M, Azenha M, Aguiar J and Castro Gomes JP (2016) Experimental and numerical studies of hybrid PCM embedded in plastering mortar for enhanced thermal behaviour of buildings. Energy 94: 250-261, http://dx.doi.org/10.1016/ j.energy.2015.10.131.

O'Callaghan PW and Probert SD (1977) Sol-air temperature. Applied Energy 3(4): 307-311.
Rubitherm GmbH (2012) Technologies is the Leading Manufacturer of Innovative Phase Change Material - RT. Rubitherm $\mathrm{GmbH}$, Berlin, Germany.

Sayyar M, Weerasiri RR, Soroushian P and Lu J (2014) Experimental and numerical study of shape-stable phase-change nanocomposite toward energy-efficient building constructions. Energy and Buildings 75: 249-255, https://doi.org/10.1016/j.enbuild.2014.02.018.

Shafie-Khah M, Kheradmand M, Javadi S et al. (2016) Optimal behavior of responsive residential demand considering hybrid phase change materials. Applied Energy 163: 81-92, https://doi.org/10.1016/ j.apenergy.2015.11.013.

Vaz Sá A, Azenha M, de Sousa H and Samagaio A (2012) Thermal enhancement of plastering mortars with phase change materials: experimental and numerical approach. Energy and Buildings 49: 16-27, https://doi.org/10.1016/j.enbuild.2012.02.031.

Vicente R and Silva T (2014) Brick masonry walls with PCM macrocapsules: an experimental approach. Applied Thermal Engineering 67(1-2): 24-34.

Waqas A and Zia UD (2013) Phase change material (PCM) storage for free cooling of buildings - a review. Renewable and Sustainable Energy Reviews 18: 607-625, https://doi.org/10.1016/ j.rser.2012.10.034

Zhou D, Zhao C and Tian Y (2012) Review on thermal energy storage with phase change materials (PCMs) in building applications. Applied Energy 92: 593-605, https://doi.org/10.1016/j.apenergy. 2011.08.025.

\section{How can you contribute?}

To discuss this paper, please email up to 500 words to the editor at journals@ice.org.uk. Your contribution will be forwarded to the author(s) for a reply and, if considered appropriate by the editorial board, it will be published as discussion in a future issue of the journal.

Proceedings journals rely entirely on contributions from the civil engineering profession (and allied disciplines). Information about how to submit your paper online is available at www.icevirtuallibrary.com/page/authors, where you will also find detailed author guidelines. 